
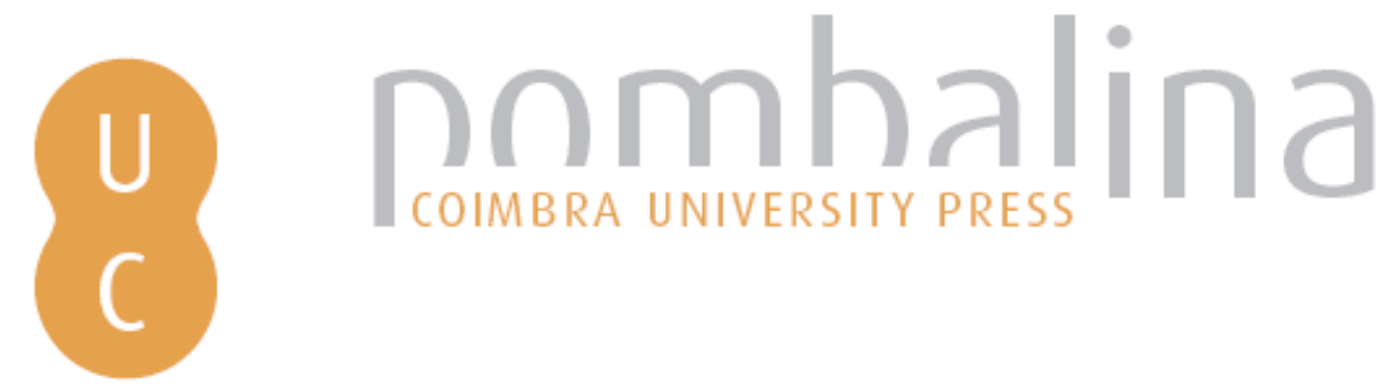

\title{
Eficácia e eficiência no processo de recuperação da informação no catálogo eletrônico de uma biblioteca universitária Brasileira
}
Autor(es):
Ornellas, Virgínia Ávila
Publicado por: Imprensa da Universidade de Coimbra
URL
persistente:
URI:http://hdl.handle.net/10316.2/31941
DOI:
DOI:http://dx.doi.org/10.14195/978-989-26-0869-3_31
Accessed : $\quad$ 26-Apr-2023 13:45:40

A navegação consulta e descarregamento dos títulos inseridos nas Bibliotecas Digitais UC Digitalis, UC Pombalina e UC Impactum, pressupõem a aceitação plena e sem reservas dos Termos e Condições de Uso destas Bibliotecas Digitais, disponíveis em https://digitalis.uc.pt/pt-pt/termos.

Conforme exposto nos referidos Termos e Condições de Uso, o descarregamento de títulos de acesso restrito requer uma licença válida de autorização devendo o utilizador aceder ao(s) documento(s) a partir de um endereço de IP da instituição detentora da supramencionada licença.

Ao utilizador é apenas permitido o descarregamento para uso pessoal, pelo que o emprego do(s) título(s) descarregado(s) para outro fim, designadamente comercial, carece de autorização do respetivo autor ou editor da obra.

Na medida em que todas as obras da UC Digitalis se encontram protegidas pelo Código do Direito de Autor e Direitos Conexos e demais legislação aplicável, toda a cópia, parcial ou total, deste documento, nos casos em que é legalmente admitida, deverá conter ou fazer-se acompanhar por este aviso.

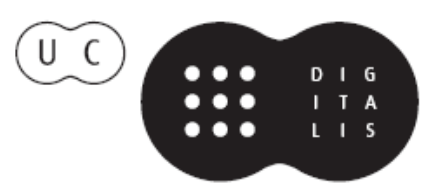


Maria Manuel Borges

Elias Sanz Casado

Coordenação

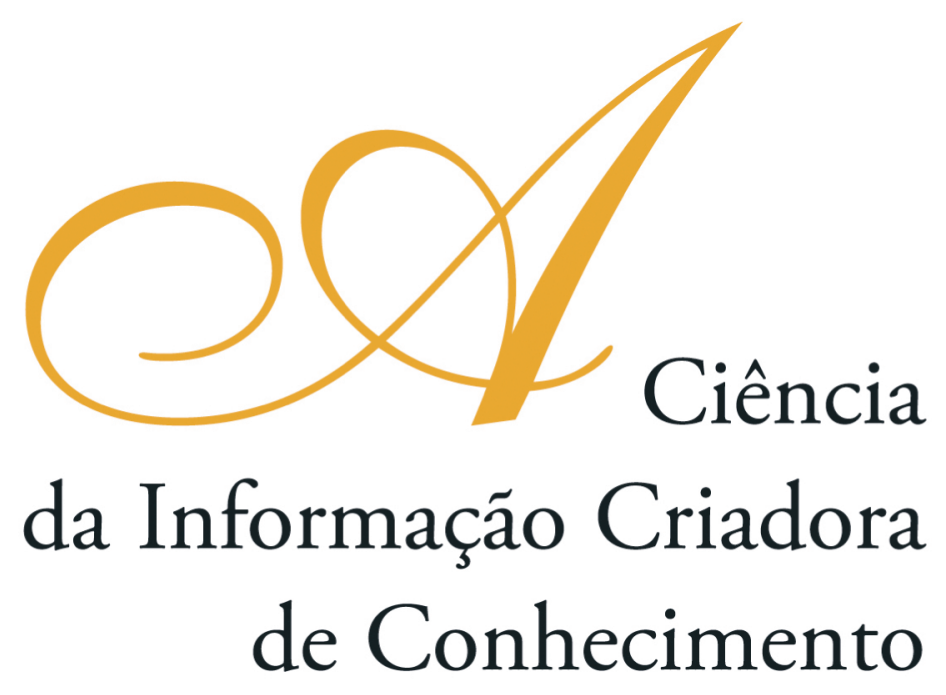

Vol. I I

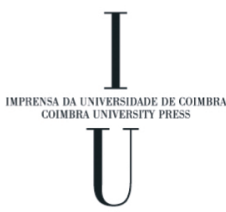

- COImbra 2009 


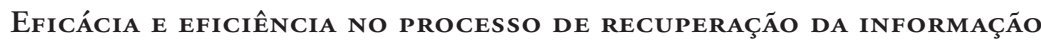 \\ No CATÁlogo eletrônico de uma Biblioteca Universitária Brasileira
}

\author{
Virgínia Ávila Ornellas \\ Universidade Federal de Mato Grosso do Sul (Brasil)
}

\title{
Introdução
}

A automação e a informatização das operaçóes dos serviços prestados a usuários e/ou clientes nos âmbitos comercial, educacional, científico e de lazer no mundo moderno gera economia financeira e de tempo ao homem, proporcionando conforto e comodidade. Esta é uma característica intrínseca da evolução tecnológica vivenciada na atual sociedade da informação e do conhecimento. Todavia, para que o usuário obtenha sucesso em suas operaçóes com o computador é necessário ter conhecimento a respeito de como interagir com as ferramentas disponíveis. Uma das características desta necessidade vincula-se à busca de informação. Neste sentido, a recuperação da informação disponibilizada por uma biblioteca é ferramenta essencial para a interação entre a formação de conhecimento e o contínuo processo de desenvolvimento de uma sociedade. Dentro desta perspectiva, a biblioteca universitária atuando como geradora de infra-estrutura bibliográfica e documental aos cursos de graduação e pós-graduação, às pesquisas e aos serviços vinculados à universidade, exerce papel social fundamental por auxiliar diretamente na formaçáo do aluno de ensino superior, futuro profissional que atuará junto à sua comunidade.

\section{Objetivos e metodologia}

Este trabalho analisa a eficácia e a eficiência do processo de recuperaçáo da informação no catálogo eletrônico da Biblioteca Central da Universidade Federal de Mato Grosso do Sul (UFMS), mediante o levantamento e análise de elementos que envolvem a busca, a recepção e a interpretação da informação pelo usuário. A partir disso, objetiva-se verificar o relacionamento entre usuário e catálogo eletrônico, refletir se, após dez anos de automação dos serviços da Biblioteca Central da UFMS (1996-2006), o catálogo eletrônico ainda corresponde às necessidades dos usuários e contemporizar se não seria o momento oportuno para uma reavaliação do Serviço de Recuperação da Informação. A metodologia utilizada constitui-se de referenciais teóricos e da técnica de coleta de dados. As principais diretrizes de pensamento que direcionam esta pesquisa relacionam-se aos estudos de Fredrerick Lancaster sobre indexação de informação, às reflexões de Heloísa Rowley quanto ao sistema de gerenciamento eletrônico de bibliotecas, e aos trabalhos sobre gestão da informação de Maria Almeida. O instrumento de coleta de dados refere-se à aplicaçáo de um 
questionário composto de nove questôes - sendo oito de cunho quantitativo e uma de cunho qualitativo, enfocando três tópicos específicos: identificação dos usuários, recuperação da informação e usuário e o catálogo eletrônico. Trata-se de uma pesquisa quantitativa e qualitativa no que diz respeito ao tipo de questionário utilizado. As perguntas fechadas apresentaram valores suscetíveis à tabulação dos dados, os quais foram dispostos em tabelas para análise quantitativa mais apurada. A partir da aplicação da pergunta aberta, levantaram-se dados subjetivos através das respostas que foram agrupados de acordo com os aspectos semelhantes.

\section{Resultados obtidos e discussão}

Durante a investigação, destacou-se a disposição do corpo discente de manifestar seu ponto de vista sobre a biblioteca, apresentando respostas longas e detalhadas. Isso atesta a consciência desses alunos a respeito da importância da biblioteca para atingir os propósitos de sua formação. Sobre a relação do usuário com o catálogo, constatouse uma recepção positiva na maior parte das respostas. Entretanto, foram localizados problemas pontuais relacionados à dificuldade de alguns em conseguir a informação desejada, tanto pela falta de conhecimento sobre a utilização adequada das ferramentas de busca quanto pela carência de recursos mais modernos - apontados pelos inquiridos - que, se integrados ao catálogo eletrônico, proporcionariam melhores resultados. Outro aspecto revelador circunscreve-se à falta de habilidade dos usuários quanto a termos de buscas derivados por assunto, considerados mais complexos. Essa dificuldade desdobra-se em dois problemas principais: a não capacitação do aluno para lidar com este tipo de segmento de recuperação da informação e a falta de conhecimento sobre significados derivados da área em que está estudando. Dessa maneira, o auxílio direto de funcionários da biblioteca a esses usuários se mostra fundamental para tornar esse recurso mais eficiente e eficaz. Muitas vezes, a preocupação com a geração e atualização constante do sistema de informaçáo de uma biblioteca universitária leva os profissionais responsáveis por este serviço a centrarem suas atividades mais exclusivamente nos procedimentos internos que constituem o processo de gerenciamento de dados, devido à grande demanda exigida por uma instituição de ensino superior do porte da UFMS. Diante disso, ocorre certo distanciamento em relação às reais necessidades dos usuários. No estudo em questão, constatou-se essa realidade, tendo em vista, entre outros fatores, o desenvolvimento acelerado da tecnologia que se aperfeiçoa rápida e constantemente. Ainda que esta biblioteca esteja sempre atenta às inovaçôes tecnológicas, verificou-se a necessidade de aperfeiçoamento do seu catálogo eletrônico devido ao alcance que o usuário de hoje tem a outras formas de pesquisa fora da circunferência da instituição onde estuda. Porém, ainda que existam outros tipos de consultas mais rápidos fora da universidade, é preciso atentar para a demanda do acadêmico. Ele pode localizar a informação em outras fontes de busca, mas o acesso material e a sua consequente leitura, estudo e aprendizado depende da utilização do acervo da biblioteca. Neste sentido, instaura-se um problema que exige a atençáo dos bibliotecários responsáveis pela recuperação da informação no sentido de manter um contato mais próximo com o usuário, visando a atender os seus propósitos de pesquisa. Estes que muitas vezes não são supridos pelo catálogo eletrônico disponível devido à carência de atualizaçóes 
que permitam à interface do catálogo tornar-se mais interativa e, principalmente, à falta instrução adequada do usuário sobre as particularidades das ferramentas de busca. Esse diálogo se tornará promissor não apenas para proporcionar mais eficácia e eficiência à geração da informação como também para tornar o espaço da biblioteca uma comunidade mais interativa socialmente entre os indivíduos que a compóem, profissionais da informação e usuários.

\section{Referências bibliográficas}

ALMEIDA, M. C. B. de. Planejamento de bibliotecas e serviços de informaçáo. Brasília: Briquet de Lemos, 2000.

CÔRTE, A. R. et al. Avaliaçáo de softwares para bibliotecas e arquivos. 2. ed. rev. e ampl. São Paulo: Polis, 2002.

LANCASTER, F. W. Indexaçáo e resumos: teoria e prática. 2. ed. Brasília: Briquet de Lemos, 2004.

ROWLEY, J. Biblioteca eletrônica. Brasília: Briquet de Lemos, 2002. 